\title{
Intimate Partner Violence, Women Autonomy And Modern Contraceptive Use In Nigeria: Evidence From 2008 And 2013 National Demographic Health Survey
}

\author{
Adeola O Raji *, Oluwafemi A Popoola ** \\ * Center for Communication, Programs, Johns Hopkins University, Baltimore \\ *** Department of, Community Medicine, University College Hospital, Ibadan \\ DOI: 10.29322/IJSRP.11.12.2021.p12035 \\ http://dx.doi.org/10.29322/IJSRP.11.12.2021.p12035
}

\begin{abstract}
Introduction: Intimate partner violence (IPV) has significant negative effects on women's health. IPV can be associated with outcomes such as unintended pregnancy, abortion and non-use of contraception. Hence, this study seeks to investigate the association between intimate partner violence, women autonomy and modern contraceptive use in Nigeria.
\end{abstract}

Method: This study analysed data from the 2008 and 2013 National Demographic and Health Survey (NDHS) focused on women of reproductive age (15-49 years). A total of 33,383 and 38,522 women were screened in 2008 and 2013 respectively. In 2008, the NDHS employed a two-stage cluster sampling technique while a three-stage stratified sampling technique was used for the 2013 Study. Data was analysed using SPSS version 21

Results: The mean age of respondents was $28.7 \pm 9.5$ years and 28.9 \pm 9.7 years in 2008 and 2013 respectively. A marginal increase in the use of contraceptives was observed in all except among women aged 40-44 years. Intimate partner violence prevalence among women in rural area decreased from $26.0 \%$ in 2008 to $19.2 \%$ in 2013. Conversely, the prevalence of IPV in urban areas increased from $21.1 \%$ in 2008 to $22.8 \%$ in 2013. In 2008, IPV across the zones was found to be higher in the Southern regions (except South West-11.7\%) compared to the Northern regions. Women in the richest and lowest wealth quintiles had the lowest prevalence $(19.5 \%$ and $13.1 \%)$ in 2008 and 2013 respectively. In 2013, those who are experiencing at least one form of violence was positively associated with the use of modern contraceptive which no association in 2008. Women autonomy was also found to be significantly associated with the use modern contraceptives.

Conclusion: Female autonomy and IPV experience are associated with modern contraceptive use. Future research should explore the possibilities incorporating of IPV mitigating support for women adopting modern contraceptive use.

\section{INTRODUCTION}

$I^{\mathrm{n}}$ ntimate partner violence (IPV) is a human violation and major public health issue worldwide, it is however hidden because it is often unrecognized and underreported (Devries et al., 2013; García-Moreno et al., 2005). At least one in three women (35\%) has experienced intimate partner violence globally. It was also stated that about $38 \%$ of murders experienced by women globally were committed by intimate partners (WHO, 2013). IPV as described by Nigeria Population Commission (2014) is a form of conflict between family or household members that involves physical harm, sexual assault, economic abuse, intimidation and threats. Both men and women can be perpetrator or survivor of violence, but studies have shown that majority of victims are females (Interagency Gender Woking Group, 2006) while vast majority of perpetrators are male (Rennison and Welchans, 2000). Despite the global investment in family planning which has raised the contraceptive use rates in some countries (Creanga et al., 2011), Nigeria still low contraceptive use rates, all forms $13 \%$, modern methods $10 \%$ as at 2013 . The fertility rate is therefore high at 5.5 in 2013 (NPC and ICF, 2014). Although, according to the report of PMA 2020, the prevalence of contraceptive use in some Nigerian states had increased for some states. In developing countries about 222 million women were reported to have unmet need for modern contraception (Singh and Darroch, 2012). In Nigeria, $16 \%$ of her women had unmet need for contraception (NPC and ICF, 2014). About 35\% of women consider arguing with husband or sex refusal as a valid reason for wife beating. This level acceptance of IPV by women in developing countries may be an important obstacle to the promotion of reproductive health programmes like contraceptives utilization and others (Singh et al., 2009).

Nigeria now has a target of doubling her contraceptive utilization to $36 \%$ by 2018 (Ejembi et al., 2015). Achieving this goal calls for assessment of the factors that affect the uptake of contraceptive among Nigerian women. Hence the need to assess the role intimate partner violence and women's autonomy play in the utilization of contraception among Nigerian women. This may establish a need to provide IPV support in family planning clinic services (WHO, 2011).

Violence against women can have weighty effects on the woman's health and it includes injury, mental illness, unintended pregnancy, abortion, depression, homicide and non-use of contraception (WHO 2013; Hindin et al, 2008,). Some of these consequences can last lifetime. IPV could come in various forms such as physical, sexual, emotional and psychological violence. In addition to conflicting reports on the association between IPV and contraceptive use reported globally, there has been paucity of information on this association in Nigeria in spite of available data. Hence, this study seeks to investigate the association 
between intimate partner violence, women autonomy and modern contraceptive use in Nigeria.

\section{METHODS}

Study Design: Secondary data analysis of the National Demographic and Health Survey (NDHS), a nationally representative population based cross sectional survey for the years 2008 and 2013.

Study Area: Nigeria is the most populous country and the $14^{\text {th }}$ largest by land mass in Africa. The population and Housing Census conducted by the National Population Commission (NPC)in 2006 placed the country's population at 140,431,790. Presently, Nigeria is made up of 36 states and a Federal Capital Territory (Abuja), grouped into six geopolitical zones (North Central, North-East, North-West, South-East, South-South, and South-West) with wide differences between the Northern and the Southern parts of the country. There are 774 constitutionally recognized local government areas (LGAs) in the country. More than half $(54 \%)$ of the population resides in rural areas. About $57 \%$ of females are enrolled in school compared with $71 \%$ males (NPC and ICF, 2013).

Study Population: The women of reproductive age (15-49 years) from the 2008 and 2013 Nigeria Demographic Health Survey (NDHS) rounds.

Inclusion criteria: All women age 15-49years who were interviewed were either residents of the households or visitors present in the households on the night before the survey, all currently using modern contraceptive women and a subsample of one eligible woman in each household was randomly selected to be asked additional questions regarding domestic violence.

Exclusion criteria: Women using non-modern forms of contraceptives and women who were pregnant.

Sample size: In the 2008 NDHS, a total of 36,298 households were selected and of these 34,644 were occupied and 33,383 were successfully interviewed, yielding a response rate of 98 percent. In the interviewed households, a total of 34,596 women were identified to be eligible for the individual interview and subsets of 21,468 women were asked questions on domestic violence.

In 2013 the NDHS, a total of 40,320 households were selected, 38,904 were found to be occupied and 38,522 were successfully interviewed, giving a household response rate of 99 percent. Also, a subsample of one eligible woman in each household was randomly selected to be asked additional questions regarding domestic violence, a total of 39,902 women age 15-49 were identified as eligible for individual interviews, and 98 percent of them were successfully interviewed which was 38,948. For domestic violence, a total 27,634 women were interviewed as only one woman was selected per household.

Sampling Technique: In 2008, the NDHS employed a twostage cluster sampling technique. At the first stage each state was subdivided into local government areas (LGAs) and each LGA was divided into localities. Each locality was then subdivided into Enumeration Areas (EA). The primary sampling unit (PSU), referred to as a cluster in the NDHS was defined on the basis of EAs from the 2006 EA census frame. 888 clusters were then selected using stratified two-stage cluster design. Representative sample of 36,800 households was then selected for the survey, with a minimum target of 950 completed interviews per state. At the second stage an average of 41 households was selected in each cluster by probability systematic sampling. All women age 15-49 who were either permanent residents of the households or visitors present in the households on the night before the survey were eligible to be interviewed. In addition, a subsample of one eligible woman in each household was randomly selected to be asked additional questions about domestic violence.

The sampling technique for 2013 NDHS was a three-stage stratified sample. At stage one, 893 localities were selected with probability proportional to size and with independent selection in each sampling stratum. During stage two, one EA was randomly selected from most of the selected localities with an equal probability selection. In a few larger localities, more than one EA was selected. In total, 904 EA were selected. After the selection of the EAs and before the main survey, a household listing operation was carried out in all of the selected EAs. The household listing consisted of visiting each of the 904 selected EAs. At stage three, 45 households were selected in every urban and rural cluster through equal probability systematic sampling based on the newly updated household listing.

Method for Data Collection: Secondary data sets of the 2008 and 2013 NDHS were used for this study and an interviewer assisted questionnaire was used. Three questionnaires were used in the NDHS surveys: Household Questionnaire, Woman's Questionnaire and Man's Questionnaire. The content of these questionnaires were based on the model questionnaires developed by the MEASURE DHS programme (NPC and ICF, 2014). The model questionnaires were modified individually to the national requirements, this was done in the consultation with the consortium of government ministries and agencies, nongovernmental organizations and international donors to reflect relevant issues such as family planning. Domestic violence, HIV/AIDS and maternal and child health. Stakeholders' meetings to discuss the questionnaires extensively preceded each of the surveys. The questionnaires were then translated into three major Nigerian languages - Hausa, Igbo and Yoruba and were pretested, refined and finalized for the survey.

The NDHS programme developed a standard domestic violence questionnaire that was used for this survey. The development of this instrument was guided by the available research on valid and reliable measurement of domestic violence and by guidelines set out by the World Health Organization (2001) on the ethical collection of such sensitive information. The part of the module specific to spousal (husband or cohabiting partner) violence uses a modified version of the Conflict Tactics Scales (Straus, 1990). The women's questionnaire captured: background characteristics (age, region, education, wealth, media exposure), knowledge, source and use of family planning methods, women's work and husbands' background characteristics, women's decision making, intimate partner violence.

Data analysis and management: Data was analysed using SPSS version 21. Socio-demographic characteristics, IPV and contraceptive use are presented as frequencies and rates using tables. Association between variables is expressed as odds ratio at $\mathrm{p}<0.05$. A logistic regression was fitted to derive the adjusted odds of IPV on contraceptive use controlled for women's decisionmaking autonomy and socio demographic characteristics. For the current report, women who reported at least one of these forms of violence were classified as having experience IPV while those 
who reported none of these acts were classified in the no violence group. Weighting factor was applied to each woman's record to adjust for non-response.

Ethical consideration: Study did not capture women's identity, so no ethical approval was sought. However, an authorization to download the dataset was obtained from the Demographic and Health Surveys (DHS) on-line archive

\section{RESULTS}

\section{Socio-demographics characteristics}

The mean age of respondents was 28.7 $\pm 9.5 y$ years and $28.86 \pm 9.7$ years in 2008 and 2013 respectively. Women who lived in rural areas were $64.3 \%$ while one-quarter of the women livedin North-West region. Of the respondents, $23.0 \%$ were of the highest wealth quintile and $35.8 \%$ had no education. In 2013, women who lived in rural areas were $57.9 \%$ while the largest $(30.5 \%)$ group of them also lived-in North-West region. Of the respondents, $22.9 \%$ were of the highest wealth quintile and $37.8 \%$ had no education.

\section{Characteristics of respondents who experienced IPV}

The overall change in IPV over these two NDHS rounds was a small decrease of $3.8 \%$. Across the age groups, there was no age bracket that with increase in experience of violence and the highest change was observed among women aged 15-19 years. When IPV change was assessed by location, the data showed a slight increase of about $2 \%$ in the experience of IPV among the urban women with a corresponding decrease of about $7.0 \%$ for rural women. Across the regions, only slight differences were observed except the for South West and North-West regions in 2008 and 2013 respectively. The highest increase in the prevalence of IPV was observed in South West region while the most significant reduction was seen in the North-West region.

Across the educational gradient, gradual decrease in IPV was seen in both years. The most significant decrease was among women with no formal education while a slight increase was observed among women with no formal education. Surprisingly, there was just a negligible change among those with the highest level of education in their experience of IPV. Across wealth quintile, the major decrease in IPV was seen among the lowest wealth quintile while the only increase occurred among the highest wealth quintile. Women with no autonomy experienced higher levels of IPV in 2008 contrary to 2013 where there was a significant reduction in the experience of IPV. In contrary, women with autonomy experienced increase in the experience of IPV in 2013 than in 2008.

Table 1: Characteristics of participants experiencing IPV

\begin{tabular}{|c|c|c|c|c|c|}
\hline \multirow[t]{2}{*}{ Variables } & \multicolumn{2}{|c|}{2008 IPV Prevalence } & \multicolumn{2}{|c|}{2013 IPV Prevalence } & \multirow[t]{2}{*}{ Change in IPV } \\
\hline & YES (\%) & 95\% C.I & $\begin{array}{l}\text { YES } \\
(\%)\end{array}$ & 95\% C.I & \\
\hline \multicolumn{6}{|l|}{ Age group } \\
\hline $15-19$ & 19.4 & $17.2-21.8$ & 12.5 & $10.4-15.0$ & -6.9 \\
\hline $20-24$ & 25.2 & $23.3-27.2$ & 20.0 & $18.2-22.1$ & -5.2 \\
\hline $25-29$ & 25.1 & $23.5-26.8$ & 21.3 & $19.7-23.0$ & -3.8 \\
\hline $30-34$ & 23.8 & $22.1-25.7$ & 23.0 & $21.3-24.9$ & -0.8 \\
\hline $35-39$ & 25.2 & $23.3-27.3$ & 22.7 & $20.8-24.7$ & -2.5 \\
\hline $40-44$ & 25.6 & $23.4-28.0$ & 22.2 & $20.0-24.5$ & -3.4 \\
\hline $45-49$ & 23.7 & $21.5-26.1$ & 17.7 & $16.0-19.5$ & -6.0 \\
\hline \multicolumn{6}{|l|}{ Locality } \\
\hline Urban & 21.1 & $19.5-22.7$ & 22.8 & $21.1-24.7$ & +1.7 \\
\hline Rural & 26.0 & $24.6-27.4$ & 19.2 & $18.0-20.5$ & -6.8 \\
\hline \multicolumn{6}{|l|}{ Region } \\
\hline North Central & 29.3 & $26.1-32.8$ & 26.4 & $23.7-29.3$ & -2.9 \\
\hline North East & 23.7 & $21.3-26.2$ & 27.4 & $24.5-30.5$ & +3.7 \\
\hline North West & 25.9 & $23.6-28.4$ & 10.2 & $8.6-12.1$ & -15.7 \\
\hline South East & 30.0 & $27.2-33.0$ & 31.5 & $27.7-35.7$ & +1.5 \\
\hline South-South & 31.3 & $28.9-33.8$ & 28.1 & $25.5-30.9$ & -3.2 \\
\hline South West & 11.7 & $10.3-13.3$ & 18.7 & $16.9-20.7$ & +7.0 \\
\hline \multicolumn{6}{|c|}{ Highest educational } \\
\hline No education & 23.7 & $22.1-25.4$ & 14.0 & $12.7-15.4$ & -9.7 \\
\hline Primary & 28.6 & $26.9-30.3$ & 27.7 & $25.9-29.6$ & -0.9 \\
\hline Secondary & 23.9 & $22.3-25.6$ & 26.9 & $25.1-28.8$ & +3.0 \\
\hline Higher & 17.2 & $14.7-20.1$ & 18.0 & $15.5-20.9$ & +0.8 \\
\hline \multicolumn{6}{|l|}{ Wealth } \\
\hline Poorest & 24.8 & $22.7-27.0$ & 13.1 & $11.2-15.3$ & -11.7 \\
\hline Poorer & 25.5 & $23.7-27.4$ & 21.0 & $19.1-23.0$ & -4.5 \\
\hline Middle & 28.7 & $26.6-30.9$ & 24.9 & $22.8-27.2$ & -3.8 \\
\hline
\end{tabular}




\begin{tabular}{llllll}
\hline Richer & 23.7 & $21.9-25.6$ & 23.2 & $21.1-25.3$ & -0.5 \\
Richest & 19.5 & $17.6-21.5$ & 21.6 & $19.6-23.8$ & +2.1 \\
Women Autonomy & & & & & \\
No & 25.4 & $24.1-26.8$ & 17.7 & $16.5-18.9$ & -7.7 \\
Yes & 20.0 & $18.6-21.4$ & 23.4 & $22.2-25.5$ & +3.4 \\
\hline
\end{tabular}

\section{Characteristics of respondents using contraceptives}

There was steady increase in the use of modern contraceptives as age increases in both years while a sharp decline among women aged 45-49 years. A marginal increase in the use of contraceptives was observed in all except among women aged 40-44 years that had a moderate decrease in the use of modern contraceptives. It was seen that there was a significant difference exist in the locality. Although, the use of modern contraceptives only increased by half a percent in the urban area while there was negligible decrease in the use among the rural area. In the region, higher prevalence of modern contraceptive use was seen in the southern areas compared to the northern areas. There was a general increase in the use of contraceptives with the highest increase in the South East and South West. Only North East region had a slight decrease in use.
Modern contraceptive use was seen to appreciate significantly across the educational gradient in both years. Although, the positive change in the contraceptive use across them was insignificant only those with no formal education had a minor negative change in the use of contraceptives. Contraceptive use was observed to increase down the wealth quintile in both years. Although, the changes in the use of modern contraceptives were insignificant, the least two quintiles had reduction in use while others had an increase use of modern contraceptives. Contraceptive was seen to be twice been used among autonomous women compared with those with no autonomy. There was no difference in the uptake of contraceptives among women without autonomy but a slight increase in use among women with autonomy.

Table 2: Characteristics of participants using contraceptives

\begin{tabular}{llllll}
\hline & \multicolumn{2}{l}{$\mathbf{2 0 0 8}$ contraceptive use } & \multicolumn{2}{l}{$\mathbf{2 0 1 3}$ contraceptive use } & Change \\
& Yes (\%) & $\mathbf{9 5 \%}$ C.I & Yes (\%) & 95\% C.I & \\
\hline contraceptive use
\end{tabular}




\begin{tabular}{llllll}
\hline Education & & & & \\
No education & 2.6 & $2.2-3.0$ & 1.7 & $1.5-2.0$ & -0.9 \\
Primary & 10.6 & $9.6-11.6$ & 12.8 & $11.9-13.8$ & +2.2 \\
Secondary & 14.6 & $13.8-15.5$ & 16.5 & $15.8-17.3$ & +1.9 \\
Higher & 25.4 & $23.3-27.7$ & 26.0 & $23.3-27.7$ & +0.6 \\
Wealth & & & & & \\
Poorest & 2.6 & $2.1-3.2$ & 0.9 & $0.7-1.2$ & -1.7 \\
Poorer & 4.5 & $3.8-5.3$ & 4.3 & $3.8-4.9$ & -0.2 \\
Middle & 8.4 & $7.6-9.2$ & 10.1 & $9.3-10.9$ & +1.7 \\
Richer & 14.3 & $13.2-15.4$ & 15.3 & $14.4-16.2$ & +1.0 \\
Richest & 20.1 & $18.8-21.4$ & 22.2 & $21.2-23.3$ & +2.1 \\
$\begin{array}{l}\text { Women's } \\
\text { autonomy }\end{array}$ & & & & & \\
No & 6.0 & $5.4-6.6$ & 5.9 & $5.5-6.3$ & -0.1 \\
Yes & 14.4 & $13.4-15.4$ & 18.2 & $17.2-19.2$ & +3.8 \\
\hline
\end{tabular}

\section{Association between IPV and modern contraceptive use}

Table 3 shows the association between the three forms of violence and modern contraceptive use in 2008 and 2013. In 2008, no forms of violence were associated with modern contraceptive uses. Although, the closest that would have been significant was physical violence which had only a 0.1 overlap. In 2013, among those experiencing at least one form of violence, $15.1 \%$ of them were using modern contraceptives which is higher than those who did not experience any form of violence which was 9.1\%. Although, women experiencing sexual violence were close to being significant but had 0.7 overlap with those who were not experiencing sexual violence.

Table 3: Association between IPV and modern contraceptive use among participants

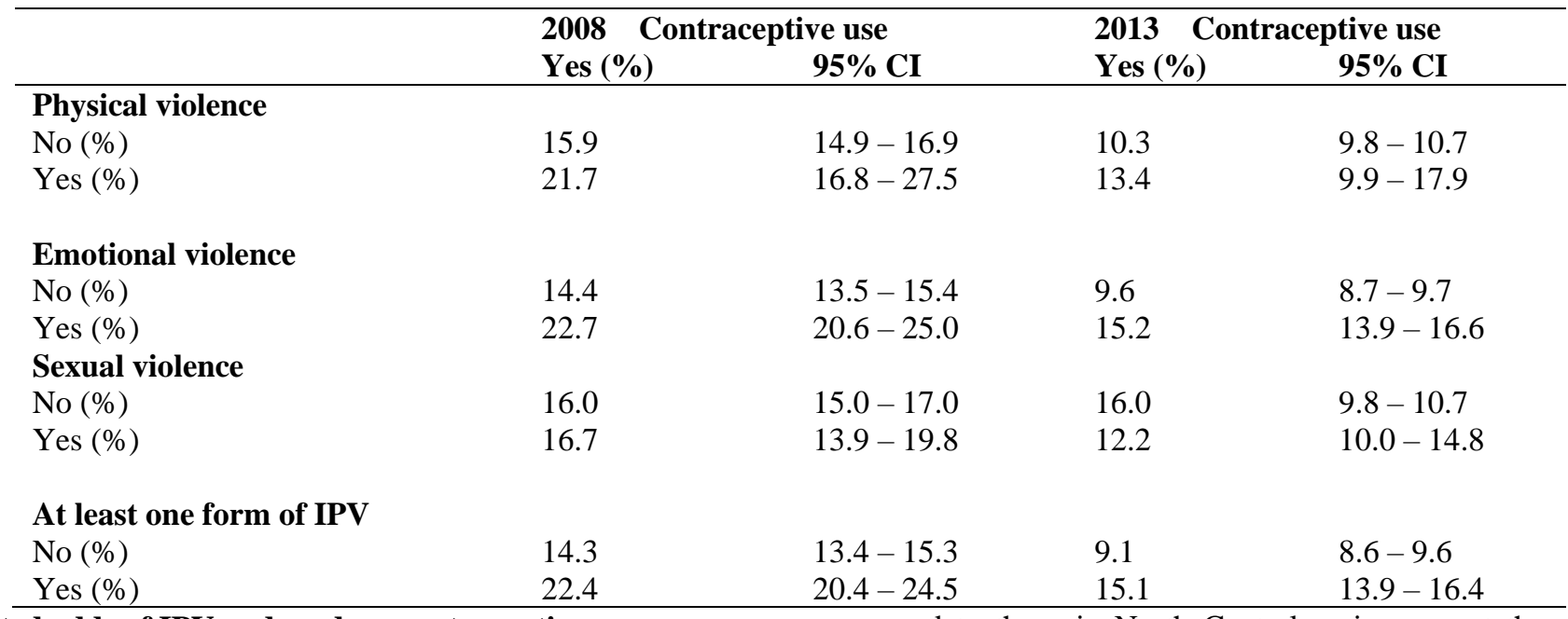

\section{Adjusted odds of IPV and modern contraceptive use}

In 2008, all the age groups were more likely to use modern contraceptive compared to those of the least age group (15-19 years). Similarly, women in the urban areas were more likely to use contraceptives compared to those in the rural areas. All regions in Nigeria were less likely to use modern contraceptives as compared to those in North Central region except those in the South-West and South-South which had no significant differences. Women in all the educational levels were about 2-4 times more likely to use modern contraceptives than those with no formal education. Women from the middle wealth quintile to the richest quintile were also more likely (about twice) than women in the 
lowest wealth quintile (reference) to use contraceptives but there was no statistically significant difference in modern contraceptives use between women in the penultimate lowest and the poorest women (reference). Autonomous women were also more likely to use modern contraceptive than those who were not autonomous.

In 2013, similar to 2008 all the age groups were more likely to use modern contraceptives than the reference group of the youngest women (15-19years). Women in all regions were less likely to use modern contraceptives compared to respondents in the North Central region the only exception was women in the South West region which had no significant difference. However, the northern zones have smaller odds which are not significant.
The southern zones have higher odds but only the South-West increase is significant. Women in the urban areas were more likely to use contraceptives compared to those in the rural areas.

Across the educational gradient, women in all the educational levels were strongly more likely to use modern contraceptives than those with no formal education. Also, all women in the wealth quintile were more likely than women in the least wealth quintile (poorest) to use contraceptives. It was also noticed that there was increasing magnitude of odds as people got wealthier. Autonomous women and those who have experienced at least one form of violence were significantly more likely to use modern contraceptive.

Table 4: Logistic regression analysis

\begin{tabular}{|c|c|c|c|c|c|c|c|c|}
\hline \multirow[b]{2}{*}{ Variables } & \multicolumn{4}{|c|}{2008} & \multicolumn{4}{|c|}{2013} \\
\hline & UAOR & $95 \% \mathrm{CI}$ & AOR & $95 \% \mathrm{CI}$ & $\begin{array}{l}\text { UAO } \\
\mathbf{R}\end{array}$ & $95 \% \mathrm{CI}$ & AOR & $95 \% \mathrm{CI}$ \\
\hline \multicolumn{9}{|l|}{ Age groups } \\
\hline $15-19 *$ & 1.0 & - & - & - & 1.0 & - & - & - \\
\hline $20-24$ & 2.9 & $2.5-3.5$ & 1.7 & $1.1-2.4$ & 3.0 & $2.6-3.5$ & 3.0 & $1.7-5.1$ \\
\hline $25-29$ & 2.8 & $2.4-3.5$ & 1.8 & $1.2-2.6$ & 2.8 & $2.5-3.3$ & 3.7 & $2.2-6.4$ \\
\hline $30-34$ & 3.0 & $2.5-3.6$ & 2.2 & $1.5-3.2$ & 3.1 & $2.7-3.6$ & 5.0 & $3.0-8.5$ \\
\hline $35-39$ & 3.1 & $2.6-3.7$ & 2.6 & $1.8-3.7$ & 3.1 & $2.7-3.6$ & 5.5 & $3.2-9.4$ \\
\hline $40-44$ & 2.5 & $2.0-3.1$ & 2.4 & $1.6-3.6$ & 3.2 & $2.7-3.8$ & 6.7 & $3.9-11.4$ \\
\hline $45-49$ & 1.5 & $1.2-1.9$ & 1.7 & $1.2-2.6$ & 1.7 & $1.4-2.0$ & 4.2 & $2.4-7.2$ \\
\hline \multicolumn{9}{|l|}{ Locality } \\
\hline Rural * & 1.0 & - & - & - & 1.0 & - & - & - \\
\hline Urban & 2.5 & $2.2-2.7$ & 1.2 & $1.1-1.3$ & 2.6 & $2.4-2.8$ & 1.2 & $1.1-1.3$ \\
\hline \multicolumn{9}{|l|}{ Region } \\
\hline North Central* & 1.0 & - & - & - & 1.0 & - & - & - \\
\hline North East & 0.3 & $0.2-0.4$ & 0.6 & $0.4-0.8$ & 0.2 & $0.2-0.2$ & 0.3 & $0.2-0.1$ \\
\hline North West & 0.2 & $0.1-0.3$ & 0.4 & $0.3-0.5$ & 0.3 & $0.2-0.4$ & 0.7 & $0.5-0.8$ \\
\hline South East & 1.0 & $0.8-1.2$ & 0.6 & $0.5-0.8$ & 1.3 & $1.1-1.4$ & 0.4 & $0.3-0.5$ \\
\hline South-South & 1.8 & $1.5-2.2$ & 0.9 & $0.7-1.1$ & 1.7 & $1.6-2.0$ & 0.7 & $0.6-0.8$ \\
\hline South West & 2.1 & $1.7-2.5$ & 1.2 & $1.0-1.4$ & 2.2 & $2.0-2.5$ & 1.2 & $1.0-1.4$ \\
\hline \multicolumn{9}{|c|}{$\begin{array}{l}\text { Highest educational } \\
\text { level }\end{array}$} \\
\hline No education* & 1.0 & - & - & - & 1.0 & - & - & - \\
\hline Primary & 4.5 & $3.7-5.3$ & 2.0 & $2.0-3.0$ & 8.5 & $7.1-10.0$ & 3.7 & $2.9-4.7$ \\
\hline Secondary & 6.5 & $5.5-7.6$ & 2.8 & $2.2-3.4$ & 11.4 & $9.8-13.2$ & 4.4 & $3.4-5.7$ \\
\hline Higher & 12.9 & $\begin{array}{l}10.6- \\
15.6\end{array}$ & 3.0 & $2.3-4.0$ & 20.2 & $17.1-23.9$ & 4.0 & $3.0-5.3$ \\
\hline \multicolumn{9}{|l|}{ Wealth } \\
\hline Poorest* & 1.0 & - & - & - & 1.0 & - & - & - \\
\hline Poorer & 1.8 & $1.4-2.3$ & 1.1 & $0.9-1.5$ & 4.9 & $3.7-6.6$ & 2.3 & $1.5-3.5$ \\
\hline Middle & 3.4 & $2.7-4.4$ & 1.6 & $1.2-2.1$ & 12.2 & $9.3-16.0$ & 4.0 & $2.7-6.0$ \\
\hline Richer & 6.3 & $5.0-8.1$ & 2.1 & $1.6-2.9$ & 19.6 & $15.0-25.5$ & 4.6 & $3.0-6.9$ \\
\hline Richest & 9.6 & $8.6-12.1$ & 2.6 & $1.9-3.5$ & 31.1 & $19.9-40.5$ & 5.5 & $3.6-8.4$ \\
\hline \multicolumn{9}{|c|}{ Women's autonomy } \\
\hline No* & 1.0 & - & - & - & 1.0 & - & - & - \\
\hline Yes & 2.6 & $2.4-3.0$ & 1.2 & $1.1-1.4$ & 3.5 & $3.2-3.9$ & 1.3 & $1.1-1.5$ \\
\hline \multicolumn{9}{|c|}{$\begin{array}{l}\text { At least one form of } \\
\text { IPV }\end{array}$} \\
\hline No* & - & - & - & - & 1.0 & - & - & - \\
\hline Yes & - & - & - & - & 1.8 & $1.6-2.0$ & 2.0 & $1.3-3.2$ \\
\hline
\end{tabular}

* Reference group 


\section{DISCUSSION}

This study showed that in 2008, women in the age group 4044yearswhich represented about $9 \%$ of the total women experienced highest prevalence of IPV across the age groups while the highest prevalence in 2013 was observed among women aged 30-34 years which was $14 \%$ of the total women. The greatest reduction $(7 \%)$ in IPV was seen among women aged $15-19$ years which represented one-fifth of the women. The observed change in the experience of IPV across the age groups showed that there was decrease in the experience of IPV in all the age groups.

Women who lived in rural areas had higher prevalence of IPV experience in 2008 conversely to 2013 where the urban women experienced higher prevalence of IPV experience. It was also observed that there was migration of people from the rural area to the urban area, this could be that the women who experienced IPV were the ones who migrated to the urban area which led to the increase in the prevalence of IPV in the urban area. There were varying changes across the regions. In the northern region, there was increase in experience of IPV in the North-East while a decrease in North-West and north central. This reduction in the experience of IPV in the northern region occurred in about twothird of the women living in the region which was a significant reduction in the experience of IPV among them.

In the southern region, South-South had reduction in the experience of IPV while an increase in women's experience of IPV in South-East and the highest increase in South-West. SouthSouth women were the most who experienced the highest rate of IPV in the regions in 2008 while South-East women had the highest rate of IPV. Although, the maximum decrease in the experience of IPV was found in the North-West region while the greatest increase was observed in the South-West region. This was similar to some findings (Aimakhu et al 2009; Uthman et al 2009; Obi and Ozumba, 2009). Future implication may mean that the northern region may achieve zero violence against women earlier that the southern region, the reason behind this is unknown. The highest prevalence of IPV was found among women with primary level of education in both years. It was seen that both women with primary and no form of education had a reduction in experience of IPV. This was about half of the population that experienced reduction of IPV.

The largest reduction was found among women with primary education with a moderate increase in the experience of IPV among women who had secondary or higher levels of education. Similarly, across the wealth quintile, there was a general decrease in women's experience of IPV except in the richest quintile which had an increase. Women of the middle wealth quintile were observed to experience the most IPV among women in both years. In 2008, higher prevalence of IPV was found among women without autonomy. Contrary, women with autonomy suffered more IPV than those without autonomy in 2013. Generally, increase in IPV was found among the most educated and richest women, the reason could be because they have decision making autonomy thereby, they tend to disrespect/disobey their partners and the partners responding violently in return.
It was revealed that there was a gradual increase in contraceptive use across the age groups and then a decrease in use among age 44-49 years in the two years. This result was similar to other studies by Fagbamigbe et al., (2015) and Ejembi, (2015). These changes might simply indicate behaviour changes due to real or perceived reductions in pregnancy risk with the onset of climacteric menopause. Across the region, the northern region had the lowest contraceptive use rates. High level of illiteracy and polygamous type of family can be the reason for this low uptake in the northern part. This low rate of contraceptive use was also reported by Avidime et al (2010). In his study conducted in Kaduna, Nigeria attributed this to the desire of large family size. In terms of educational gradient, the least level of uptake of modern contraceptives were women with no education and highest with women with the highest level of education. This could be due to their exposure to media, health facilities and locality. Contraceptive use also increased across the wealth quintile. Autonomous women and those living in the urban area had higher prevalence of modern contraceptive use than their counterparts.

This study revealed that there was reduction in the use of modern contraceptives among women aged 40-44 years in 2013 compared with 2008 while there was slight increase in uptake in the other age groups. This could be as a result of their decrease in sexual activities. Rural women were observed to have decrease use in modern contraceptives as compared to those the urban area that had an increase use of contraceptives. There was a general increase in contraceptive use across the regions except for North East where a significant decrease was observed, this result could be due to the Boko Haram insurgence in the region which has destroyed most social infrastructure in the region.

Across the wealth quintiles, an increase in the use of modern contraceptive was observed in all the quintiles except the two lowest levels. Women with no education showed a reduction in the use of modern contraceptives unlike others who had increase in contraceptive use. Women with no autonomy were seen to have reduced use of modern contraception while women who had autonomy had a significant increase in the use of contraception. This is similar to the findings of Rahman et al 2014 among Bangladeshi women.

Bivariate analysis shows that in both years age, wealth, education, locality and region were statically significant to the use of contraception. This is similar to findings in Ethiopia (Lakew et al, 2013; O'Hara et al, 2013) that older, more educated and being wealthy were strongly predicted the use of modern contraceptive. This study showed that there was no form of association between IPV and modern contraceptive use in 2008 similar to this finding is a study by Ogunjuyigbe et al (2010) that violence was not a factor influencing the use of contraceptives in South west Nigeria. In 2013, a positive association was found among women who experience at least one form of violence and their use of modern contraceptives. This is in line with Alio et al (2009) that found that women in sub-Saharan Africa were more likely to use contraceptives. Contrary result was observed in a systematic review which showed that women who experienced IPV were less likely to use contraceptives especially male dependent ones (Maxwell et al., 2015).

This study found lower odds with the use of modern contraceptives in the northern regions which is similar to the findings of other studies. This could be due to the fact that the 
northern region is predominantly dominated by Muslims in which other studies have found negative association between Muslim communities and modern contraceptive use (Ejembi et al 2015; Adebayo et al. 2012 and Oye-Adeniran et al. 2006).

Other studies have also shown that urban locality is associated with increased use of modern contraceptives which is similar to the findings in this study. The reasons could be because of enhanced infrastructure and increased access to health services. Wealth was also found to be positively associated with the use of modern contraceptives.

It was also found that female education was positively associated with use of modern contraceptives. Improvements in women's educational attainment increase the likelihood of use of modern contraceptives. This may be associated with the role of female education in empowering women through enhancing their autonomy and participation in decision-making, positively modifying health-seeking behaviour and building social capital through expansion of social networks. The positive association found between female education and contraceptive use is consistent with other studies conducted in developing countries (Arokiasamy and Cassen 2004; Hailu 2015). Education also increases women's employment opportunities, which can result in increased economic independence and expanded autonomy in decision-making.

This study revealed that women's autonomy had influence on the use of modern contraceptives. In both years, women autonomy was found to be positively associated with the use (Mosfequr et al 2014; Saleem and Pasha, 2009). This can be attributed to independent power in making decisions with(out) the partner's input. Decision making autonomy was based on her involved in decision-making regarding mobility, financial decisions and decisions on use of contraceptives were measured. Similar to other findings, women who had decision making autonomy (participate in decision-making in these dimensions) were significantly more likely to use modern contraceptives.

\section{CONCLUSION}

This study revealed that there was no age category with an increase in experience of violence, with the biggest shift occurring among women aged 15-19 years. In addition, there was a minor rise of around $2 \%$ in IPV experience among urban women, compared to a fall of nearly 7.0 percent among rural women. In both years, the usage of modern contraceptives increased steadily as women's ages increased, with a steep reduction among women aged 45-49. Although, in the urban region, the usage of modern contraceptives climbed by half a percent, there was a minor drop in the rural area. In 2013, 15.1 percent of people who had experienced at least one kind of violence used contemporary contraceptives, which was greater than those who had not experienced any form of violence. In 2013, women with autonomy had more IPV experience than they had in 2008. Contraception was used twice as much by independent women as it was by nonautonomous women. In both years, women of all ages were more likely to use contemporary contraception than women in the youngest age group.

\section{REFERENCES}

[1] Adebayo, S., Gayawan E., Ujuju C., and Ankomah A. (2012)."Modelling geographic variation in use of modern family planning methods among women of reproductive age in Nigeria."Journal of Biosocial Science 00:1 (28).

[2] Aimakhu C.O., Olayemi O., Iwe C.A.B., Oluyemi F.A., Ojoko I.E., Shoretire K.A., Adeniji R.A., \&Aimakhu V.E., (2004). Current causes and management of violence against women in Nigeria.Journal of Obstetrics and GynaecologyVol. 24 ,Iss. 1

[3] Alio, A. P., Daley, E. M., Nana, P. N., Duan, J., \& Salihu, H. M. (2009) Intimate partner violence and contraception use among women in SubSaharan Africa. International Journal of Gynecology \& Obstetrics, 107(1), 35-38

[4] Arokiasamy, P., McNay, K., \& Cassen, R. H. (2004). Female education and fertility decline: Recent developments in the relationship. Economic and Political Weekly, 4503-4507.

[5] Avidime S., Aku-akai L., Mohammed A. Z., Adaji S., \& Ejembi S. C., (2010). Fertility Intentions, Contraceptive Awareness and Contraceptive Use among Women in Three Communities in Northern Nigeria, 2010(3), 65-70.

[6] Creanga, A. A., Gillespie, D., Karklins, S., \& Tsui, A. O. (2011). Low use of contraception among poor women in Africa: an equity issue. Bulletin of the world Health Organization, 89, 258-266.

[7] Devries K., Mak J., García-Moreno C., Petzold M., Child J., et al. (2013) The global prevalence of intimate partner violence against women. Science 340: 1527-1528. doi: 10.1126/science. 1240937 PMID:23788730

[8] Ejembi C.L., Tukur D., and Aliyu A.A., (2015).Contextual Factors Influencing Modern Contraceptive Use in Nigeria.DHS Working Papers No. 120. Rockville, Maryland, USA: ICF International.

[9] Fagbamigbe A. F., Adebowale A. S., \& Morhason-bello I., (2015). Survival analysis of time to uptake of modern contraceptives among sexually active women of reproductive age in Nigeria, 1-11. http://doi.org/10.1136/bmjopen-2015-008371

[10] García-Moreno C., Watts C., Jansen H., Ellsberg M., Heise L., (2003).Responding to violence against women: WHO's Multicounty Study on Women's Health and Domestic Violence. Health Human Rights:6(2):11227.

[11] Hailu, T.G. 2015. "Determinants of cross-sectional variation in contraceptive prevalence rate in Ethiopia: A multilevel modelling approach." American Journal of Mathematics 5 (3):95110

[12] Hindin M.J., (2008). “Understanding women's attitudes towards wife beating in Zimbabwe". Bulletin of the World Health Organization81: 501-508.

[13] Lakew Y., Reda A. A., Tamene H., Benedict S., \&Deribe, K. (2013). Geographical variation and factors influencing modern contraceptive use among married women in Ethiopia: evidence from a national population based survey. Reproductive Health, 10, 52. https://doi.org/10.1186/17424755-10-52.

[14] Maxwell L., Devries K., Zionts D., Alhusen J. L., \& Campbell, J. (2015) Estimating the Effect of Intimate Partner Violence on Women' s Use of Contraception: A Systematic Review and Meta-Analysis, 1-25. PLoSONE10(2): e0118234. doi:10.1371/journal.pone.0118234.

[15] MosfequrR., Golam M., Aminul H., (2014). Women's household decisionmaking autonomy and contraceptive behavior among Bangladeshi women.Science direct.Sexual \& Reproductive Healthcare Volume 5, Issue 1, Pages 9-15

[16] National Population Commission (NPC) (Nigeria) and ICF Macro (2014) Nigeria Demographic and Health Survey 2013. Abuja, Nigeria: National Population Commission and ICF Macro.

[17] O’Hara K., Tsai L.C., Carlson C.E., \&Haidar Y.M., (2013).Experiences of intimate partner violence and contraception use among ever-married women in Jordan.Eastern Mediterranean Health Journal $=$ La Revue de Santé de La Méditerranée Orientale = Al-Majallah Al-Șiḥ̣īyah Li-Sharq, Al-Mutawassit, 19(10), 876-82. Retrieved from http://www.ncbi.nlm.nih.gov/pubmed/24313152

[18] Obi S.N.,\&Ozumba B.C., (2007). Factors associated with domestic violence in south-east Nigeria. Journal of Obstetrics and GynaecologyVol. 27 ,Iss. 1,2007 .

[19] Ogunjuyigbe, P.O., Akinlo, A. \& Oni, G.O. J Fam Viol (2010) Violence against Women as a Factor in Unmet Need for Contraception in Southwest Nigeria. 25:123. https://doi.org/10.1007/s10896-009-9275-y. 
[20] Oye-Adeniran, B., Adewale I.F., UmohA.V., Oladokun A., Gbadegesin A., and EkanemE.E.. (2006). "Community-based study of contraceptive behavior in Nigeria." African Journal of Reproductive Health 10 (2):90-104.

[21] Rennison C.M., Welchans S., (2000). Intimate Partner Violence. Washington (DC): Bureau of Justice Statistics, U.S. Department of Justice; NCJ.

[22] Saleem, A., \& Pasha, G. (2009). Modeling of the women's reproductive behavior and Predicted Probabilities of Contraceptive Use in Pakistan. University of Azad Jammu \& Kashmir, Pakistan.

[23] Singh S., and Darroch J.E., (2012). "Adding It Up: Costs and Benefits of Contraceptive Services - Estimaates 2012, New York, NY", Guttmacher Institute and United Nations Population and (UNFPA)," Retrieved from < http://www. guttmacher. org/pubs/AIU-2012-estimates.pdf

[24] Singh S., Wulf D., Hussain R., Bankole A., SedghG.,(2009). Abortion Worldwide: A Decade of Uneven Progress. http://www.guttmacher.org/pubs/Abortion-Worldwide.pdf

[25] Uthman, O. A., Lawoko, S., \& Moradi, T. (2009). BMC International Health and Factors associated with attitudes towards intimate partner violence against women : a comparative analysis of 17 sub-Saharan countries, 15 http://doi.org/10.1186/1472-698X-9-14

[26] World Health Organization (WHO) (2011).Intimate partner violenceduring pregnancy sheet.http://www.who.int/reproductivehealth/publications/violence/en/index .html

[27] World Health Organization (WHO). 2014. Family planning fact sheet. http://www.who.int/ mediacentre/factsheets/fs351/en/

[28] World Health Organization (WHO). Intimate partner violence: Facts 2002 http://www.who.int/violence_injury_prevention/violence/world_report/facts heets/en/ipvfacts.pdf.(accessed December 21, 2013)

[29] World Health Organization (WHO). Preventing Intimate partner and sexual violence against women: Taking action and generating evidence. 2010. http://www.who.int/reproductivehealth/publications/violence/97892415640 07/en/(accessed March 18, 2014)

\section{AUTHORS}

First Author - Adeola O Raji, Center for Communication Programs, Johns Hopkins University, Baltimore Second Author - Oluwafemi A Popoola, Department of Community Medicine, University College Hospital, Ibadan

Correspondence Email Address: rajiadeolar09@gmail.com 